\title{
Novel SLC5A2 Mutations and Genetic Characterization in Korean Patients with Familial Renal Glucosuria
}

\author{
Weon Kyung Lee, M.D. ${ }^{1}$ \\ Seung Hwan Oh, M.D. ${ }^{2}$ \\ Woo Yeong Chung, M.D.' \\ Department of Pediatrics ${ }^{1}$, Inje \\ University College of Medicine, Busan, \\ Korea, Department of Laboratory \\ Medicine $^{2}$, Inje University College of \\ Medicine, Busan, Korea
}

\section{Corresponding author: Woo Yeong Chung, M.D. Department of Pediatrics, Inje University College of Medicine, Bokji-ro 75, Busanjin- gu, Busan 47392, Korea \\ Tel: +82-51-890-6280 \\ Fax: +82-51-895-7785 \\ E-mail: chungwy@chol.com}

Received: 17 October 2017

Revised: 21 October 2017

Accepted: 23 Ocotber 2017

\begin{abstract}
This is an open-access article distributed under the terms of the Creative Commons Attribution Non-Commercial License (http:// creativecommons.org/licenses/by-nc/4.0/) which permits unrestricted non-commercial use, distribution, and reproduction in any medium, provided the original work is properly cited.
\end{abstract}

Purpose: Familial renal glucosuria (FRG, OMIM \#233100) is a rare but relatively benign genetic condition characterized by persistent isolated glucosuria with a normal blood glucose level. We report three additional SLC5A2 mutations and examine their phenotypic and genetic characteristics in a Korean FRG cohort. We also reviewed the literature and summarized the genotypes of all Korean patients with FRG.

Methods: A genetic analysis was conducted by directly sequencing all 14 exons of the $S \angle C 5 A 2$ gene and their flanking regions in six unrelated Korean children with FRG and their family members. Novel non-synonymous single-nucleotide polymorphisms were identified and compared with known mutations that are repeatedly detected in the Korean population.

Results: We found two novel mutations [c.274G >A (G92S) and c.1168C > (L390F)] and one known [c.1382G $>A$ (S461N)] mutation in each family and one recurrent mutation [c.1346G>A (G449D) (rs768392222)] in two pedigrees. The recurrent G449D was predicted to be"possibly damaging," with a score of 0.883 in Polyphen2, while G92S, L390F, and S461 N were predicted to be "probably damaging," with scores of $1.000,0.999$, and 0.996 , respectively.

Conclusions: Two novel, one previously reported, and one recurrent mutation were identified in six Korean FRG pedigrees as causative mutations of renal glucosuria. Sequence variations in the $S L C 5 A 2$ gene were frequently detected in children with persistent isolated glucosuria. A long-term follow-up of this FRG cohort is needed to understand how these specific SGLT2 mutations impair kidney function and energy homeostasis.

Key words: SGLT2, Glucose, Glucosuria, Mutation

\section{Introduction}

Familial renal glucosuria (FRG, OMIM \#233100) is a rare genetic condition characterized by persistent isolated glucosuria with a normal glucose level in blood and a relatively benign condition ${ }^{1,2)}$. Mutations in the SLC5A2 gene that encodes glucose transporter in the renal proximal tubule are known to be a cause of this genetic condition and these mutations have been reported to be distributed across the entire gene region without a hot spot ${ }^{3,4}$. The lower affinity, high-capacity sodium-glucose cotransporter 2 (SGLT2), located in the early proximal convoluted tubule segment $\mathrm{S}$, plays a major role in the glucose reabsorption mechanism ${ }^{5-7)}$. SGLT2 enables glucose homeostasis by reabsor- 
bing the filtered glucose (approximately $180 \mathrm{~g} /$ day) and excreting glucose $<0.5 \mathrm{~g} /$ day in adults ${ }^{6,7}$. The SLC5A2 gene is mapped to $16 \mathrm{p} 11.2$ and has 14 exons encoding 672 amino acids ${ }^{8,9)}$. The degree of glucosuria depends on the mutation site, type and zygosity, so the clinical course varies according to the affected individual. Therefore, the codominance mode of inheritance with variable penetrance has been suggested ${ }^{1,2}$. Here, we added six patients to the Korean FRG cohort, reporting two additional novel SLC5A2 mutations and reviewed the genetic characteristics in this study and the literature.

\section{Materials and methods}

\section{Study population}

Blood samples from six Korean children and their families with isolated glucosuria were collected from May 2014 to June 2016 for the SLC5A2 mutation analysis. Written informed consent was obtained from all subjects and their family members for the molecular diagnostic tests whenever possible. This study was approved by the Institutional Review Board of Busan Paik Hospital and conducted according to the guidelines of the Declaration of Helsinki.

Five probands and one child were incidentally found to have glucosuria during a school health examination survey and a fever workup, respectively. Their mean age (four males and two females) was 10.8 years (range, 7-14 years). Diagnostic criteria were: (1) total 24-hour urine glucose excretion $>0.5 \mathrm{~g} / 1.73 \mathrm{~m}^{2}$; (2) normal glucose metabolism; 3) normal renal function without other pathological signs, such as hematuria, proteinuria, hyperphosphaturia, hypercalciuria, or metabolic acidosis.

\section{SLC5A2 mutation analysis}

Human genomic DNA was prepared from peripheral blood samples using the QIAamp DNA Blood Mini Kit (Qiagen, Hilden, Germany). A genetic analysis was conducted by directly sequencing all 14 exons of the SLC5A2 gene and their flanking regions in the six unrelated Korean children with FRG and their family members using the ABI 3130 Genetic analyzer (Applied Biosystems, Foster City, CA, USA) with the BigDye 3.1 Sequencing Kit (Applied Biosystems). Novel non-synonymous, single-nucleotide polymorphisms were identified and compared with the G449D recurrently detected in the Korean population. When an identical mutation has been reported separately over three times, we consider it as a recurrent (non-random) mutation.

\section{Literature review and in silico prediction of altered} protein function

A comprehensive review of the literature and a mutation database (Human Gene Mutation Database, http//www. hgmd.org) was conducted regarding the $S L C 5 A 2$ sequence variations in FRG. To predict the deleterious effect of sequence variations, the substitutions found in all sequence variations detected in the Korean FRG cohort in this study and the literature were submitted to the web-based programs Sorting Intolerant From Tolerant (http://sift.jcvi. org) and Polyphen-2 (http://genetics.bwh.harvard.edu/ pph2) and analyzed.

\section{Results}

\section{Phenotypic analysis}

None of probands in the FRG family had symptoms or signs of diabetes mellitus. No abnormal results were observed in the biochemistry, electrolytes, or a urinalysis, except glucosuria. No growth disturbances, polydipsia, polyuria, or dehydration were detected. Table 1 lists the

Table 1. Phenotypic Characteristics of the Patients in this Study

\begin{tabular}{lccccc}
\hline Patient & Age $(\mathrm{yr})$ & Gender & Plasma glucose $(\mathrm{mg} / \mathrm{dL})$ & HbA1C & Urinary glucose excretion $\left(\mathrm{g} / 1.73 \mathrm{~m}^{2} / 24 \mathrm{hr}\right)$ \\
\hline 1 & 12 & M & 81 & 5.3 & 1.53 \\
2 & 11 & F & 85 & 5.7 & 2.25 \\
3 & 9 & M & 91 & 5.5 & 58.67 \\
4 & 12 & F & 89 & 5.4 & 5.88 \\
5 & 7 & M & 107 & 4.9 & 6.16 \\
6 & 14 & M & 83 & 5.3 & 7.09 \\
\hline
\end{tabular}


clinical characteristics of these probands. No aminoaciduria was detected in the tested probands (patients 2, 3, and 4).

\section{SLC5A2 mutation and in silico analyses}

We found two novel mutations (c.274G>A (G92S) and c.1168C > T (L390F)) and one known mutation (c.1382G $>$ A $(\mathrm{S} 461 \mathrm{~N})$ ) mutation in each family and one recurrent mutation (c.1346G>A (G449D) (rs768392222)) in two pedigrees (Fig. 1). The two novel variants were not found in any variation databases, including dbSNP, ExAc, and 1000G, or the literature (Table 2). One pedigree revealed no mutation in the coding sequence or its flanking regions. The recurrent G449D was predicted to be 'possibly damaging' with a score of 0.883 in Polyphen-2, while the novel G92S and L390F and the known $\mathrm{S} 461 \mathrm{~N}$ were predicted to be 'probably damaging' with scores of 1.000, 0.999, and 0.996, respectively.

\section{Discussion}

In this study, sequence variations were detected frequently $(83 \%, 5 / 6)$ by mutation analysis of the SLC5A2 gene in six unrelated families with persistent isolated glucosuria. Two novel (G92S and L390F), one known (S461N), and one recurrent (G449D) mutation were identified as causative mutations of renal glucosuria. Two novel and one known sequence variations were considered probably damaging, with a higher impact score in the prediction tools, compared with that of the known recurrent mutation. Despite a thorough evaluation of one pedigree with glucosuria, no mutations were detected in the entire coding region or adjacent intronic segments. A heterozygous large deletion or unknown mutation may be present in the other associated gene epigenetic alterations. In previous studies, wild type individuals also had the FRG pedigree ${ }^{1,8}$.

To date, over 70 different SLC5A2 gene mutations have been reported and most are missense mutations and are suggested to be private (restricted to a single individual or pedigree $)^{3,10-14)}$. However, some of the mutations, such as IVS7+5G>A (c.885+5G>A), G449D (rs768392222), and P246S (rs773359240), have been reported recurrently ${ }^{3,12,14)}$. In a study with a cohort of 23 Korean children with FRG, 19 mutations were detected, which were also private or novel, except for the recurrent G449D in seven pedigrees ${ }^{14)}$. The present study reconfirms that most of SLC5A2 gene mutations are private and that $\mathrm{G} 449 \mathrm{D}$ is a recurrent mutation in Korean FRG. IVS7+5G $>A$ has been reported with the highest frequency in other ethnic group ${ }^{1,15)}$. Zhao et al.
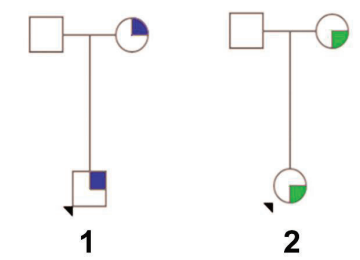

wild type
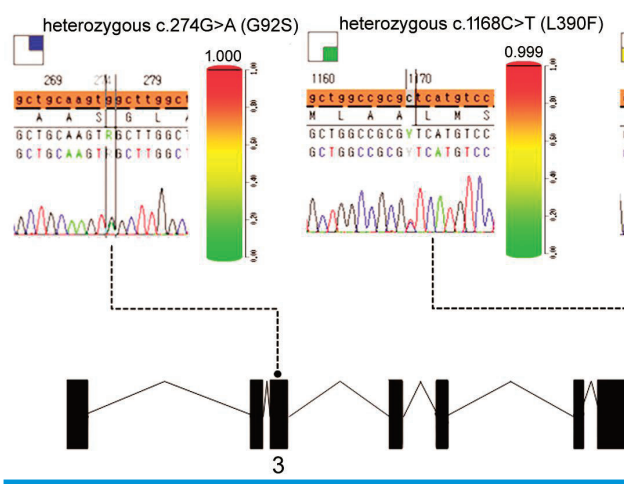
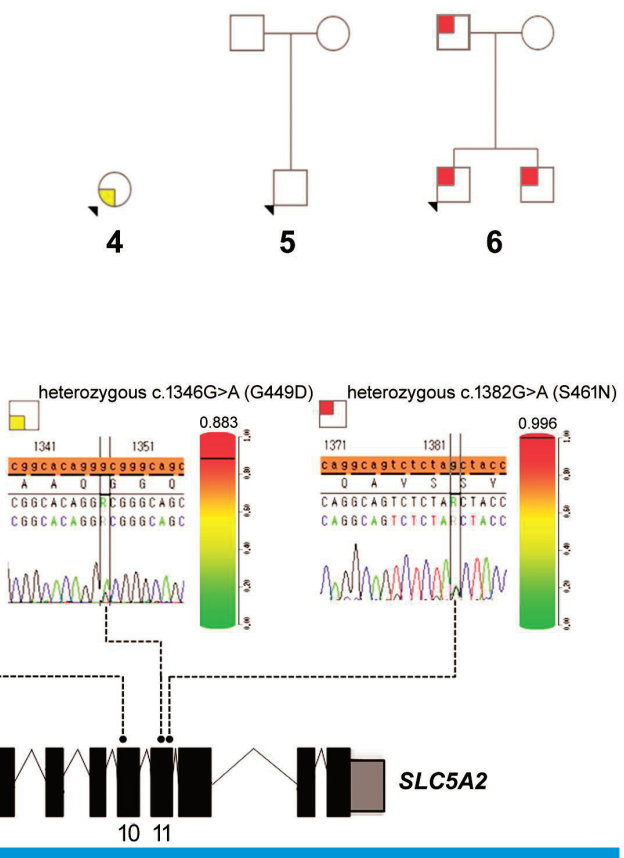

Fig. 1. Pedigrees with renal glycosuria and representative electropherograms of SLC5A2 mutation sites in this study. Dashed lines denote locations of the SLC5A2 gene mutations. PolyPhen-2 Human Var scores are displayed with heatmap charts on the right side of each electropherogram. 
reported a 22-bp deletion in intron 7 (c.886(-10_-31)del), which was suggested to be the second high-frequency mutation (eight Chinese families) following IVS7 $+5 \mathrm{G}>\mathrm{A}$; thus, they concluded that this high frequency deletion in intron 7 should be screened in more patients with FRG and uniallelic or negative SLC5A2 mutations ${ }^{9}$. Although we reanalyzed the flanking regions of intron 7 , we could not find any mutations in our FRG cohort.

FRG is generally an asymptomatic disorder except for glucosuria. Furthermore, glucosuria has been reported to be mild in most patients with FRG. However, some cases, especially those with homozygous or compound heterozygous mutations, have heavy glucosuria ${ }^{1)}$. In those cases, severe glucosuria can be accompanied by generalized aminoaciduria ${ }^{16)}$. Hyperuricosuria and hypercalciuria can also be secondary signs of FRG ${ }^{17-19)}$. In this study, only one of six patients with FRG showed severe glucosuria, but aminoaciduria, hyperuricosuria, or hypercalciuria was not present. One patient with the recurrent G449D mutation showed severe glucosuria, whereas another patient with the same mutation showed only mild glucosuria, indicating the variable expressivity of this genetic disorder.

A new class of anti-hyperglycemic drug targeting the SGLT2 has been introduced to treat type 2 diabetes. This new class of anti-hyperglycemic drug has several advantages to deliver a beneficial effect on body weight and blood pressure. Use of SGLT2 inhibitors to diabetes mimics the beneficial effect of dysfunctional SGLT2 in FRG individuals. SGLT2 inhibitors can cause the same kinds of complications such as dehydration and urinary infections, which have been also reported in the severe form of $\mathrm{FRG}^{3,20)}$. Inhibition or dysfunction of SGLT2 has pleiotropic effects on renal physiology ${ }^{7,21,22)}$. The long-term outcome of patients with FRG is excellent, but the beneficial effect on metabolic homeostasis is unclear ${ }^{11,23,24)}$. Thus, a long-term follow-up is needed to elucidate the life-long consequences of inhibiting or altering SGLT2. In addition, the mutation profiles of SLC5A2 gene could provide useful clues for the protein function and new drug targets.

In summary, we identified five mutations, including two

Table 2. SLC5A2 Sequence Variations Detected in the Korean Pedigree in this Study and the Literature

\begin{tabular}{|c|c|c|c|c|c|c|c|c|c|}
\hline Nucleotide change & Protein change & $\mathrm{SIFT}$ & $\begin{array}{l}\text { PolyPhen2* } \\
\text { HumDiv }\end{array}$ & $\begin{array}{l}\text { PolyPhen2* } \\
\text { HumVar }\end{array}$ & $\begin{array}{c}\text { Prediction } \\
\text { (Polyphen2* HumVar) }\end{array}$ & $\begin{array}{l}\text { Frequency (ExAc, } \\
\text { 1000G) [East Asian] }\end{array}$ & $\mathrm{dbSNP}$ & $\begin{array}{l}\text { HGMD } \\
\text { identifier }\end{array}$ & Literature \\
\hline C.170T>C & p.L57P & 0 & 1.000 & 1.000 & probably damaging & & & CM127450 & 14) \\
\hline c. $274 \mathrm{G}>\mathrm{A}$ & p.G92S & 0 & 1.000 & 1.000 & probably damaging & & & - & This study \\
\hline C.320T>C & p.L107P & 0.01 & 1.000 & 0.999 & probably damaging & & & CM127446 & 14) \\
\hline c. $409 C>T$ & p.R137C & 0 & 1.000 & 0.999 & probably damaging & $3 / 121260$ [0/8642] & rs373185306 & CM127441 & 14),1) \\
\hline c.736C $>T$ & p.P246S & 0.52 & 1.000 & 0.999 & probably damaging & $7 / 120584[5 / 8554]$ & rs 773359240 & CM127442 & 14) \\
\hline c. $867 \mathrm{G}>\mathrm{C}$ & p.W289C & 0.02 & 0.241 & 0.157 & benign & & & CM127445 & 14) \\
\hline c.938G $>A$ & p.G313D & 0 & 1.000 & 1.000 & probably damaging & & & CM127447 & 14) \\
\hline c. $.979 C>T$ & p.L327F & 0.47 & 1.000 & 1.000 & probably damaging & 8/121094 [0/8630] & rs757582393 & CM127439 & 14) \\
\hline c. $.983 \mathrm{~T}>\mathrm{G}$ & p.M328R & 0 & 0.998 & 0.993 & probably damaging & & & CM127443 & 14) \\
\hline c.1162delG & p.A388Pfs*48 & - & - & & - & & & - & 13) \\
\hline C. $1168 C>T$ & p.L390F & 0.02 & 1.000 & 0.999 & probably damaging & & & - & This study \\
\hline c. $1346 \mathrm{G}>\mathrm{A}$ & p.G449D & 0.15 & 0.993 & 0.883 & possibly damaging & $3 / 119132$ [2/8550] & rs7683922222 & CM034974 & This study 1,14$)$ \\
\hline c. $1357 \mathrm{~T}>\mathrm{A}$ & p.F453l & 0.07 & 1.000 & 0.998 & probably damaging & & & CM127449 & $1,14)$ \\
\hline c. $1382 \mathrm{G}>\mathrm{A}$ & p.S461N & 0 & 0.999 & 0.996 & probably damaging & & & CM127444 & This study14) \\
\hline c.1418_1432dup15 & p.473_477dupLALFV & - & - & - & - & & & Cl127456 & 14) \\
\hline c. $1430 \mathrm{~T}>\mathrm{G}$ & p.V477G & 0.01 & 0.999 & 0.969 & probably damaging & & & CM127452 & 14) \\
\hline c. $1435 C>G$ & p.R479G & 0.01 & 0.976 & 0.878 & possibly damaging & & rs387906682 & CM111865 & 14) \\
\hline c.1475_1476insC & p.L493Pfs*74 & - & - & - & - & & & - & 14) \\
\hline c. $1499 \mathrm{~T}>\mathrm{G}$ & p.L500R & 0 & 0.624 & 0.261 & benign & & & CM127451 & 14) \\
\hline c. $1507 \mathrm{G}>\mathrm{A}$ & p.E503K & 0 & 0.952 & 0.278 & benign & & & CM127448 & 14) \\
\hline c. $1540 C>T$ & p.P514S & 0.09 & 1.000 & 0.996 & probably damaging & 13/120800 [13/8620] & rs565909305 & CM127440 & 14) \\
\hline c. $1732 C>T$ & p.Q578* & - & - & - & - & & rs778838521 & CM127453 & 14) \\
\hline c.1798delC & p.Q600Rfs*18 & - & - & - & - & & & CD127454 & 14) \\
\hline c.1894_1895ins6 & p.[A634E;634_635ins2] & - & - & - & - & & & Cl127516 & 14) \\
\hline
\end{tabular}

*Polyphen-2 v2.2.2r398 (accessed November 7, 2016). 
novel, one known, and one recurrent missense mutation, in six Korean FRG pedigrees. This study expands the knowledge about the genetic characteristics of $S L C 5 A 2$ in Korean FRG. A long-term follow-up of this FRG cohort is needed to understand how these specific SGLT2 mutations impair kidney function and energy homeostasis and to predict which domains would be targets of SGLT2 inhibitors.

\section{Conflicts of interest}

No potential conflict of interest relevant to this article was reported.

\section{References}

1. Santer R, Kinner M, Lassen CL, Schneppenheim R, Eggert P, Bald $M$, et al. Molecular analysis of the SGLT2 gene in patients with renal glucosuria. J Am Soc Nephrol 2003; 14:2873-82.

2. Van den Heuvel LP, AssinkK, Willemsen M, Monnens L. Autosomal recessive renal glucosuria attributable to a mutation in the sodium glucose cotransporter (SGLT2). Hum Genet 2002;111:544-7.

3. Santer R, Calado J. Familial renal glucosuria and SGLT2: from a mendelian trait to a therapeutic target. Clin J Am Soc Nephrol 2010;5:133-41.

4. Elsas LJ, Rosenberg LE. Familial renal glycosuria: a genetic reappraisal of hexose transport by kidney and intestine. J Clin Invest 1969;48:1845-54.

5. Kanai Y, Lee WS, You G, Brown D, Hediger MA. The human kidney low affinity Na+/glucose cotransporter SGLT2. Delineation of the major renal reabsorptive mechanism for D-glucose. J Clin Invest 1994;93:97-404.

6. Brown GK. Glucose transporters: structure, function and consequences of deficiency. J Inherit Metab Dis 2000;23:237-46.

7. Wright EM. Renal $\mathrm{Na}(+)$-glucose cotransporters. Am J Physiol Renal Physiol 2001;280:F10-8.

8. Calado J, Loeffler J, Sakallioglu O, Gok F, Lhotta K, Barata J, et al. Familial renal glucosuria: SLC5A2 mutation analysis and evidence of salt-wasting. Kidney Int 2006;69:852-5.

9. Calado J, Soto K, Clemente C, Correia P, Rueff J. Novel compound heterozygous mutations in SLC5A2 are responsible for autosomal recessive renal glucosuria. Hum Genet 2004;114:314-6.

10. Zhao X, Cui L, Lang Y, Liu T, Lu J, Wang C, et al. A recurrent deletion in the SLC5A2 gene including the intron 7 branch site responsible for familial renal glucosuria. Sci Rep 2016;6:33920.

11. Yu L, Xu Q, Hou P, Zhang H. Decreased expression and function of sodium-glucose co-transporter 2 from a novel C-terminal mutation: a case report. BMC Nephrol 2016;17:31.

12. Yu L, Hou P, Lv JC, Liu GP, Zhang H. Novel SLC5A2 variants contribute to renal glucosuria in Chinese families: abnormal expression and dysfunction of variant SLC5A2. Hum Mutat 2015;36:79-86.

13. Lee YW. Clinical and genetic analysis in a patient with primary renal glucosuria: Identification of a novel mutation in the SLC5A2 gene. Exp Ther Med 2013;6:1532-4.

14. Lee H, Han KH, Park HW, Shin Jl, Kim CJ, Namgung MK, et al. Familial renal glucosuria: a clinicogenetic study of 23 additional cases. Pediatr Nephrol 2012;27:1091-5.

15. Calado J, Sznajer Y, Metzger D, Rita A, Hogan MC, Kattamis A, et al. Twenty-one additional cases of familial renal glucosuria: absence of genetic heterogeneity, high prevalence of private mutations and further evidence of volume depletion. Nephrol Dial Transplant 2008;23:3874-9.

16. Magen D, Sprecher E, Zelikovic I, Skorecki K. A novel missense mutation in SLC5A2 encoding SGLT2 underlies autosomal-recessive renal glucosuria and aminoaciduria. Kidney Int 2005;67:3441.

17. Scholl-Burgi S, Santer R, Ehrich JH. Long-term outcome of renal glucosuria type 0: the original patient and his natural history. Nephrol Dial Transplant 2004;19:2394-6.

18. Schneider D, Gauthier B, Trachtman H. Hypercalciuria in children with renal glycosuria: evidence of dual renal tubular reabsorptive defects. J Pediatr 1992;121:715-9.

19. Aires I, Santos AR, Pratas J, Nolasco F, Calado J. Hypouricaemia and hyperuricosuria in familial renal glucosuria. Clin Kidney J 2013;6: 523-5.

20. Oemar BS, Byrd DJ, Brodel J. Complete absence of tubular glucose reabsorption: a new type of renal glucosuria (type 0). Clin Nephrol 1987;27:156-60.

21. Chen LH, Leung PS. Inhibition of the sodium glucose co-transporter-2: its beneficial action and potential combination therapy for type 2 diabetes mellitus. Diabetes Obes Metab 2013;15:392402.

22. Kalra S. Sodium Glucose Co-Transporter-2 (SGLT2) Inhibitors: A Review of Their Basic and Clinical Pharmacology. Diabetes Ther 2014,5:355-66.

23. Ottosson-Laakso E, Tuomi T, Forsen B, Gullstrom M, Groop PH, Groop L, et al. Influence of Familial Renal Glycosuria Due to Mutations in the SLC5A2 Gene on Changes in Glucose Tolerance over Time. PLoS One 2016;11:e0146114.

24. Yu L, Hou P, Liu GP, Zhang H. Novel SLC5A2 mutation contributes to familial renal glucosuria: Abnormal expression in renal tissues. Exp Ther Med 2016;12:649-52. 